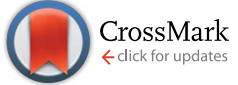

Cite this: RSC Adv., 2016, 6, 101960

\title{
Chemical forms and risk assessment of heavy metals in sludge-biochar produced by microwave- induced low temperature pyrolysis
}

\author{
Xingxin Liu, ${ }^{\text {ab }}$ Yawei Wang, ${ }^{\text {*a }}$ Chengmin Gui, ${ }^{\text {ac }}$ Ping Li, ${ }^{c}$ Junya Zhang, ${ }^{a}$ Hui Zhong ${ }^{a}$ \\ and Yuansong Wei ${ }^{\star a d}$
}

Biochar, a stable, carbon-rich solid produced during biomass pyrolysis, has been widely used in soil conditioning. A promising option to alleviate the problem of sludge management. In this study, $\mathrm{Cr}, \mathrm{Ni}$, $\mathrm{Zn}, \mathrm{Cd}, \mathrm{As}, \mathrm{Pb}$ and $\mathrm{Cu}$ were studied owing to their relatively high content in the sludge and their potential to cause environmental damage. Sludge-biochars were produced at different temperatures $\left(300{ }^{\circ} \mathrm{C}, 350{ }^{\circ} \mathrm{C}, 400{ }^{\circ} \mathrm{C}\right.$ and $450{ }^{\circ} \mathrm{C}$ ) by microwave pyrolysis. BCR (European Community Bureau of Reference: a sequential extraction) analysis reveals that speciation distribution varied largely with the different heavy metals. Three risk analysis models were adopted to evaluate the risk of heavy metals: the risk assessment code (RAC), geo-accumulation index ( $\left.I_{\text {geo }}\right)$ and potential ecological risk index $\left(E_{r}\right)$. The heavy metals risk in the biochar were lower compared with the sludge except for Pb (sludge: 4.3, biochar: 9.4-15.6) as assessed by RAC analysis. The $E_{r}$ result shows that risk from heavy metals decreased except for $\mathrm{Cd}$ (sludge: 63.53, biochar: 153.53-189.38). The Igeo model indicated that all seven heavy metals were present at higher levels in biochar than in the sludge. Although the total metal concentration in biochar increased after pyrolysis, this result indicates that heavy metal risk of microwave pyrolysis sludge-biochar should be considered alongside local soil backgrounds and speciation distributions.

Received 8th September 2016 Accepted 10th October 2016

DOI: 10.1039/c6ra22511j

www.rsc.org/advances
Pyrolysis is a promising technique and various forms of energy and resources, including non-condensable gases, bio-oil and biochar, can be recovered from sludge under high temperature and low oxygen concentrations. ${ }^{7}$ Biochar, as the main product of pyrolysis, is a recalcitrant and stabilized organic carbon. ${ }^{8}$ The specific properties of biochar include: a porous structure, large surface area, a variety of mineral components and enriched functional groups, all of which enable it to remove various inorganic or organic contaminants from solutions by absorption, such as heavy metals, mineral salts, phenolic compounds, organic pesticides and PAHs (polycyclic aromatic hydrocarbons)., ${ }^{9,10}$ Compared with traditional heating, microwave heating possesses the superiority of a rapid heating rate and energy conservation. ${ }^{11}$ In addition, biochar produced by microwave irradiation has a larger surface area and more plentiful pore structures than that obtained from traditional heating. ${ }^{7}$ Furthermore, lower microwave heating temperature is more conductive to the improvement of biochar output than traditional irradiation. ${ }^{12}$ Therefore, microwave pyrolysis is a promising technology for sewage sludge treatment and biochar preparation.

In recent years, biochar has also received increasing attention as a soil conditioner or absorbent. Many studies have indicated that biochar is rich in nutrients and carbon, and free of pathogens. Therefore, biochar can increase nutrient 
retention, improve fertilizer efficiency and raise crop production. ${ }^{6}$ However, heavy metals in the biochar may pose a risk to public health and ecological systems during its application because of their toxic and non-biodegradable nature. ${ }^{\mathbf{1 3 , 1 4}}$ One study on sludge liquefaction manifested that $70-80 \%$ of $\mathrm{Zn}$ and $\mathrm{Ni}$, and more than $80 \%$ of $\mathrm{Cd}, \mathrm{Cr}, \mathrm{Pb}$ and $\mathrm{Cu}$ from the sludge remained in the biochar. ${ }^{15}$ The research into the transformation of $\mathrm{Cr}, \mathrm{Ni}, \mathrm{Cu}, \mathrm{Cd}$ and $\mathrm{Pb}$ in sludge during the pyrolysis process showed that the heavy metals were more immobile in biochar than that in sludge, mainly because of the alkaline properties of the biochar. ${ }^{16}$ Furthermore, some previous studies have drawn the conclusion that increasing pyrolysis temperature can reduce the risk of heavy metals in the biochar. He et al. ${ }^{17}$ found that the leaching concentrations of $\mathrm{Cu}, \mathrm{Cd}, \mathrm{Zn}$ and $\mathrm{Pb}$ in biochar produced in a horizontal ceramic tube dropped sharply with increasing pyrolysis temperature in the range of $350-550{ }^{\circ} \mathrm{C}$.

The total metal content is always used as a pollution indicator. It is generally found that the behavior or mobilization capacity of heavy metals is determined by their chemical forms. ${ }^{15,18-21}$ Therefore, the Community Bureau of Reference proposed the sequential extraction procedure (BCR) to divide the heavy metals into different forms ${ }^{\mathbf{1 4 , 1 5 , 2 2 , 2 3}}$ that can also provide information about heavy metal potential reactivity, leaching potential and bioavailability in sludge or biochar. Different risk assessment models can be used to further analyze the risk of heavy metals: the risk assessment code (RAC) ${ }^{22,24}$ was applied to quantify heavy metal bioavailability in sediments, ashes, soils, and so on. Geoaccumulation index (GAI) ${ }^{\mathbf{2 4 , 2 5}}$ is another method that can be used to measure the pollution levels of heavy metals. The potential ecological risk $^{\mathbf{2 4 2 6}}$ index (RI) can evaluate the ecological risk based on the intensity, sensitivity and toxicity of the heavy metals.

Publications have mainly focused on conventional conductive heating pyrolysis and only a few studies have paid attention to the heavy metal stability after microwave irradiation. Tian et $a l .{ }^{27}$ found that microwave irradiation was more effective at immobilizing heavy metals in the sediment sludge than the traditional drying process and blast heating. It is reported that microwave-assisted hydrogen peroxide oxidation can make the metals in the sediment more stable with a lower risk to the environment. ${ }^{28}$ For land application, heavy metals are some of the top priority concerns. However, the characteristics of heavy metals in microwave pyrolysis sludge biochar are not yet clear. The risks post by heavy metals in sludge-biochar produced by microwave irradiation at low temperatures should be further analyzed.

The objectives of this article are: (1) to study whether microwave heating at low temperature can stabilize the heavy metals, and the relationship between the pyrolysis temperature and heavy metal stability. (2) To analyze the chemical speciation of heavy metals in biochars produced at low temperature using microwave heating through sequential BCR analysis. (3) To investigate the pollution intensity of heavy metals from biochar during practical application by three risk assessment methods.

\section{Experimental}

\subsection{Materials}

Dewatered sludge was obtained from the Qinghe municipal wastewater treatment plant $\left(\mathrm{A}^{2} / \mathrm{O}\right)$ process in Beijing, China (a treatment capacity of $400000 \mathrm{~m}^{3}$ per day). The initial moisture content was $83.6 \%$. The sludge was dried naturally until its water content was $12.3 \%$ and then ground into a powder that could pass through an 18 mesh sieve. The physicochemical properties of the sludge are presented in Table 1. Prior to pyrolysis, the sieved sludge powder was mixed with a $\mathrm{ZnCl}_{2}$ solution at a ratio of $2: 1\left(\mathrm{ZnCl}_{2}\right.$ : dry sludge wt\%). This ratio was chosen to maximize the specific surface area, porous structure and adsorption performance of the sludge biochar based on our preliminary experiment. $\mathrm{ZnCl}_{2}$ 's properties as a heat carrier positively influenced the initialization of pyrolysis and its addition also promotes the development of porosity in the biochar. ${ }^{29}$ The solid-liquid mixture was shaken for $24 \mathrm{~h}$ and then filtered and finally dried in a drying oven at $105{ }^{\circ} \mathrm{C}$.

Microwave pyrolysis equipment (Sineo MAS-II. Shanghai Sineo Microwave Chemistry Technology Co., Ltd., China) was used in this study. The maximum power was $1000 \mathrm{~W}$ (the power is adjustable). This microwave oven was designed with real-time temperature monitoring. The heating rate and heating up time of this oven were set up before pyrolysis while the input power varied as the temperature changed during the pyrolysis process. An infrared thermometer was used to detect the actual temperature during the process. The input power would be adjusted (increase or decrease) according to the rate of temperature rising, automatically, to ensure that the temperature rising rate was consistent with the preset value of approximate $20{ }^{\circ} \mathrm{C} \mathrm{min}^{-1}$ during the pyrolysis process. The reaction vessel was a quartz glass tube with a capacity of $1000 \mathrm{~mL}$.

\subsection{Preparation and characteristics of the biochar}

$\mathrm{N}_{2}$ was injected into the vessel at a rate of $0.5 \mathrm{~L} \mathrm{~min}^{-1}$ before pyrolysis to make sure the environment was oxygen-poor. ${ }^{7}$ During pyrolysis, the $\mathrm{N}_{2}$ flow rate was controlled at $0.1 \mathrm{~L} \mathrm{~min}^{-1}$ to ensure uniform heating conditions. Sludge is not good at absorbing microwave, while biochar can strongly absorb microwave effectively. In this study, $400 \mathrm{~g}$ dry sludge was mixed with $40 \mathrm{~g}$ biochar that was used as the microwave absorber, which was produced from the same sewage sludge in the preparative experiment. The pyrolysis temperature was raised to $300{ }^{\circ} \mathrm{C}, 350{ }^{\circ} \mathrm{C}, 400{ }^{\circ} \mathrm{C}$ and $450{ }^{\circ} \mathrm{C}$ at a rate of $20^{\circ} \mathrm{C} \mathrm{min}{ }^{-1}$, and then maintained for $1 \mathrm{~h} .{ }^{30}$ The biochar was cooled to room temperature in a nitrogen environment. The pyrolysis product was soaked in $0.5 \mathrm{M} \mathrm{HCl}$ solution for $24 \mathrm{~h}$ and then washed with deionized water until the $\mathrm{pH}$ reached 6-7. It was then dried in oven at a temperature of $105{ }^{\circ} \mathrm{C}$.

Fourier transform infrared spectroscopy (FTIR) (Nicolet 8700) was used to analyze the functional groups of the biochar. Total $\mathrm{C}, \mathrm{N}$ and $\mathrm{S}$ content in biochar were analyzed by an elemental analyzer (Vario EL III). The Brunauer-Emmett-Teller (BET) surface area, average pore size and total pore volume were measured using an automatic specific surface area and 
Table 1 The physicochemical properties and surface characteristics ${ }^{a}$

\begin{tabular}{|c|c|c|c|c|c|c|c|c|c|c|}
\hline Sample & Yield & \multicolumn{2}{|c|}{ Proximate analysis (wt\%) } & \multicolumn{4}{|c|}{ Element analysis (wt\%) } & \multicolumn{3}{|c|}{ Surface characteristics } \\
\hline SC300 & 70 & 59.12 & 41.09 & 36.87 & 0.87 & 5.81 & 6.35 & 180.57 & 5.31 & 20.17 \\
\hline SC350 & 64 & 57.14 & 44.87 & 39.38 & 0.74 & 5.59 & 7.04 & 201.42 & 4.63 & 25.32 \\
\hline SC400 & 60 & 54.34 & 46.48 & 44.68 & 0.62 & 5.43 & 8.23 & 261.03 & 4.09 & 29.01 \\
\hline
\end{tabular}

${ }^{a}$ SS: sewage sludge; SC: sludge biochar (pyrolysis temperature); BET: Brunauer-Emmett-Teller surface area; APS: average pore size; TPV: total pore volume.

micropore physical adsorption instrument (ASAP2020HD88). The heavy metal concentration was measured by inductively coupled plasma optical emission spectroscopy (ICP-OES) (OPTIMA 8300). Duplicate sampling was performed and concentrations of metals in the sludge and biochar were determined in triplicate.

\subsection{Heavy metal analysis methods (BCR)}

The sequential extraction was performed using BCR (the European Community Bureau of Reference) ${ }^{15,23}$, which has been used for several studies. The analysis procedure was divided into four steps as follows:

Step one: $F_{1}$, exchangeable fractions and those bound with carbonate. $40 \mathrm{~mL} 0.11 \mathrm{M} \mathrm{CH}_{3} \mathrm{COOH}$ solution was added to $0.5 \mathrm{~g}$ biochar in $50 \mathrm{~mL}$ polyethylene centrifuge tubes, then shaken for $16 \mathrm{~h}$ at $22{ }^{\circ} \mathrm{C}$. The residues were separated by centrifuging at $4000 \mathrm{rpm}$ for $20 \mathrm{~min}$ and then washed with $10 \mathrm{~mL}$ deionized water.

Step two: $F_{2}$, fractions bound to Fe and Mn oxides (reducible fraction). $20 \mathrm{~mL}$ of $0.1 \mathrm{M}$ hydroxyl ammonium chloride solution was adjusted to $\mathrm{pH}=2$ with $\mathrm{HNO}_{3}$. This liquid was then added to the residues from step one. The mixture was shaken for $16 \mathrm{~h}$ at $22{ }^{\circ} \mathrm{C}$. The separation and rinse of the residues employed the same methods as in step one.

Step three: $F_{3}$, fractions associated with organic matter (oxidizable fraction). $5 \mathrm{~mL} \mathrm{H}_{2} \mathrm{O}_{2}(8.8 \mathrm{M}, \mathrm{pH}=2.0-3.0)$ was added to the residues from step two, drop by drop. Next were the processes of digestion $\left(1 \mathrm{~h}\right.$ at $\left.22^{\circ} \mathrm{C}\right)$, heating $\left(1 \mathrm{~h}\right.$ at $\left.85^{\circ} \mathrm{C}\right)$ and evaporation (to make the content nearly completely dry). $25 \mathrm{~mL}$ ( $1 \mathrm{M}$ ammonium acetate solution, $\mathrm{pH}=2$ ) was added to the cooled contents. The extraction and rinse procedures were the same as in step one.

Step four: $F_{4}$, residual fractions. $5 \mathrm{~mL} \mathrm{HNO}_{3}, 3 \mathrm{~mL} \mathrm{H}_{2} \mathrm{O}_{2}$ and $5 \mathrm{~mL} \mathrm{HClO}_{4}$ were added to the residues from step three, then heated and evaporated until dry. After cooling, the residues were dissolved in $\mathrm{HNO}_{3}(5 \%)$.

Heavy metals can be divided into three categories on the basis of bioavailability: bioavailable fraction, potentially bioavailable fraction, and non-bioavailable fraction. ${ }^{18}$ The bioavailability is inclusive of the exchangeable and carbonate bounded forms $\left(F_{1}\right)$, the potential bioavailability includes the fractions bounded to Fe and $\mathrm{Mn}$ oxides and the fraction associated with organic matter $\left(F_{2}\right.$ and $\left.F_{3}\right)$, and the non-bioavailable category contained the $F_{4}$ residual fractions.

\subsection{Evaluation methods of heavy metal risk}

Three widely used methods were adopted for comparative analysis and comprehensive evaluation of the ecological risk of heavy metals in biochar. ${ }^{18,31}$ (1) The risk assessment code (RAC) can be used to indicate the heavy metal contamination intensity in the sludge and biochar. The RAC, determined as the percentage of carbonate and exchangeable-state heavy metal in the substance, can also be used to measure the biological accumulation of heavy metals. (2) The geo-accumulation index $\left(I_{\text {geo }}\right)$ quantifies the bioaccumulation of heavy metals considering the local background values of heavy metals. The background heavy metals content in Beijing were $29.8 \mathrm{mg} \mathrm{kg}^{-1}(\mathrm{Cr})$, $26.8 \mathrm{mg} \mathrm{kg}^{-1}(\mathrm{Ni}), 57.5 \mathrm{mg} \mathrm{kg}^{-1}(\mathrm{Zn}), 0.119 \mathrm{mg} \mathrm{kg}^{-1}(\mathrm{Cd})$, $7.09 \mathrm{mg} \mathrm{kg}^{-1}(\mathrm{As}), 24.6 \mathrm{mg} \mathrm{kg}^{-1}(\mathrm{~Pb})$ and $18.7 \mathrm{mg} \mathrm{kg}^{-1}(\mathrm{Cu}) .^{32}(3)$ The potential ecological risk index (RI) was used to analyze the harm caused by different heavy metals: it is a comprehensive evaluation of the ecological risk of heavy metals in biochar.

2.4.1 Risk assessment code (RAC). The RAC was used for the environmental risk assessment of heavy metals in sludge and biochar. This method is widely used in the evaluation of heavy metals in soil, sediment, ash content and liquid/gas composition. It is defined as the fraction of $F_{1}$ based on the BCR.

$$
\mathrm{RAC}=\frac{F_{1}}{C_{\mathrm{n}}} \times 100 \%
$$

where $F_{1}$ is the fraction of exchangeable and carbonate fractions and $C_{\mathrm{n}}$ is the content of the corresponding heavy metal.

The RAC can be divided into five levels of risk (Table 2): no risk (NR), low risk (LR), medium risk (MR), high risk (HR) and very high risk (VHR). ${ }^{22}$

2.4.2 Geo-accumulation index $\left(I_{\text {geo }}\right)$. The $I_{\text {geo }}{ }^{25}$ was another index that can be employed to indicate the pollution intensity of heavy metals in sludge and biochar. The detailed calculation was as follows:

$$
I_{\text {geo }}=\log _{2} \frac{C_{\mathrm{n}}}{1.5 \times B_{\mathrm{n}}}
$$

where $C_{\mathrm{n}}$ is the content of heavy metals in sludge or biochar and $B_{\mathrm{n}}$ is the local heavy metal content in soil. A factor of 1.5 is used to minimize the influence of possible variations in the local soil this method is used to analyze the impact of heavy metals on nature and mankind. The data of $I_{\text {geo }}$ was divided into seven intervals (Table 2): uncontaminated (UC), uncontaminated to moderate contamination (UC-MC), moderate contamination 
Table 2 Risk simulation results of heavy metals in biochar

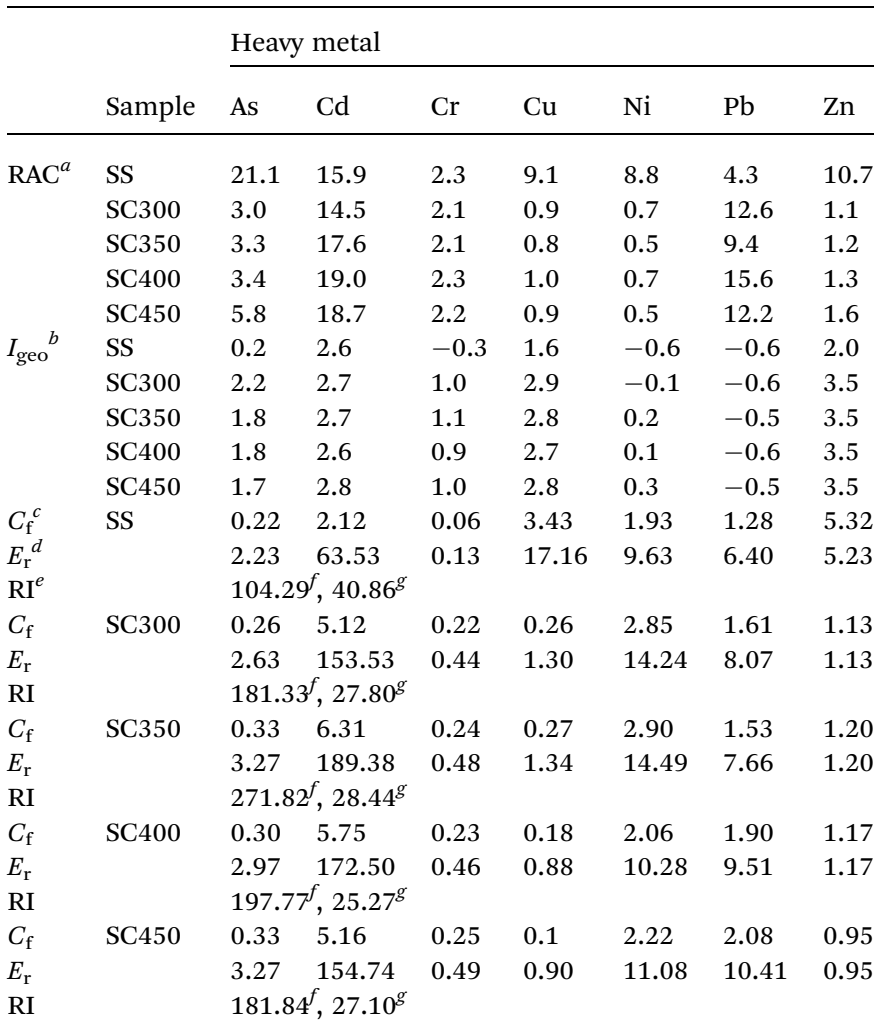

${ }^{a}$ RAC: $<1$ denotes no risk (NR); 1-10 denotes low risk (LR); 11-30 denotes medium risk (MR); 31-50 denotes high risk (HR); >50 denotes very high risk (VHR). ${ }^{b} I_{\text {geo }}:<0$ denotes uncontaminated (UC); 0-1 denotes uncontaminated to moderate contamination (UC-MC); 1-2 denotes moderate contamination (MC); 2-3 moderate contamination to heavy contamination (MC-HC); 3-4 denotes heavy contamination (HC); 4-5 denotes heavy to extreme contamination (HE-EC); $>5$ denotes extreme contamination (EC). ${ }^{c} C_{\mathrm{f}}=C_{\mathrm{D}} / C_{\mathrm{R}} \cdot{ }^{d} E_{\mathrm{r}}: \leq 5$ low risk (LE); 5-10 moderate risk (ME); 10-20 considerable risk (CE); 20-40 high risk (HE); >40 very high risk (VHE). ${ }^{e}$ RI: $<30$ denotes low risk (LR); 30-60 denotes moderate risk (MR); 60-120 denotes considerable risk (CR); >120 denotes very high risk (VHR). ${ }^{f}$ The RI based on seven heavy metals in total. ${ }^{g}$ The RI based on six heavy metals (Cd not included).

(MC), moderate contamination to heavy contamination (MC$\mathrm{HC}$ ), heavy contamination (HC), heavy to extreme contamination (HC-EC) and extreme contamination (EC).

2.4.3 Potential ecological risk index (RI). The $\mathrm{RI}^{24,26}$ can be used to evaluate the ecological risk of heavy metals in sludge and biochar. This method is based on the intensity, concentration, sensitivity and toxicity of heavy metals and is widely used in environmental chemistry and biological toxicology. The detailed calculation of RI was follows:

$$
\begin{gathered}
C_{\mathrm{f}}=\frac{C_{\mathrm{D}}}{C_{\mathrm{R}}} \\
E_{\mathrm{r}}=T_{\mathrm{r}} \times C_{\mathrm{f}} \\
\mathrm{RI}=\sum_{i=1}^{n} E_{\mathrm{r}}
\end{gathered}
$$

where $C_{\mathrm{D}}$ is the concentration of measured metal, $C_{\mathrm{R}}$ is the background concentration and $T_{\mathrm{r}}$ is the toxic response coefficient of each single heavy metal. The $T_{\mathrm{r}}$ of $\mathrm{Zn}, \mathrm{Cr}, \mathrm{Cu}, \mathrm{Ni}, \mathrm{Pb}, \mathrm{As}$ and Cd are 1, 2, 5, 5, 5, 10 and 30, respectively. $E_{\mathrm{r}}$ is the potential ecological risk of a single heavy metal and can be divided into five parts (Table 2): low risk (LE), moderate risk (ME), considerable risk (CE), high risk (HE) and very high risk (VHE). RI is the potential ecological risk of all the measured heavy metals and can be divided into: low risk (LR), moderate risk (MR), considerable risk (CR) and very high risk (VHR).

\section{Results and discussion}

\subsection{The characteristics of sludge and biochar}

The results of the proximate analysis, element analysis and surface characteristics are shown in Table 1 . The organic matter content decreased from $59.12 \%$ to $50.89 \%$, which may be caused by the increased production of bio-oil and bio-gas. In addition, the ash content increased from $41.09 \%$ to $48.06 \%$ with increasing temperature. The high ash was caused by the high content of mineral constituents in sludge and biochar. ${ }^{12}$ Ash contains minerals, so higher ash content could lead to an increase in the total heavy metal content in biochar. In the FTIR spectroscopy of sludge (Fig. 1), the peak at around $3430 \mathrm{~cm}^{-1}$ was always recorded as a result of the stretching vibrations of $-\mathrm{OH}$ in metal hydroxide or water molecules, and also could be caused by the presence of $-\mathrm{NH}$ or $-\mathrm{NH}_{2}$. The peak became weaker after pyrolysis, which indicated the decomposition of metal hydroxides, the removal of water or protein decomposition. And the exchangeable heavy metals may react during pyrolysis as follows: metal ion $\rightarrow$ metal hydroxide $\rightarrow$ metal oxide, which could cause the peak to become weaker and stabilize the heavy metals. What is more, protein decomposition could give rise to an increase in $\mathrm{C} / \mathrm{N} \cdot{ }^{33,34}$ From the surface characteristics of biochar, it could be concluded that high temperatures had a positive influence on improving the BET surface area. Compared with the heavy metal content in sludge, the contents in biochar became higher. Pyrolysis is a thermochemical decomposition that mainly generates bio-gas, biochar and bio-oil. ${ }^{35}$ Most of the heavy metals (70-80\%) remain in the biochar, except for some heavy metal release into bio-oil. ${ }^{24}$ In this study, the $\mathrm{As}, \mathrm{Zn}, \mathrm{Pb}, \mathrm{Ni}, \mathrm{Cd}, \mathrm{Cr}$ and $\mathrm{Cu}$ contents of biochar were more than $0.64,1.60,1.06,0.25,1.20,0.33$, and 0.97 times those in sludge, respectively, and most of the $\mathrm{Zn}, \mathrm{Pb}, \mathrm{Ni}$ and $\mathrm{Cr}$ remained within the biochar. Similar results have been reported in other studies. ${ }^{6,15,18,24,36}$.

\subsection{The speciation distribution of heavy metals}

The $\mathrm{BCR}^{15,23}$ for the heavy metal chemical analysis indicates the occurrence, mobilization and bioavailability of heavy metals. The heavy metals, which are exchangeable and bound with carbonate $\left(F_{1}\right)$, have the highest bioavailability and the greatest potential to cause secondary environmental pollution. ${ }^{15}$ The heavy metal contents of $F_{1}\left(\mathrm{mg} \mathrm{kg}^{-1}\right)$ are shown in Fig. 2(a). For some heavy metals, there was a higher content in biochar compared with the sludge. The $\mathrm{Cr}$ and $\mathrm{Pb}$ contents of biochar 


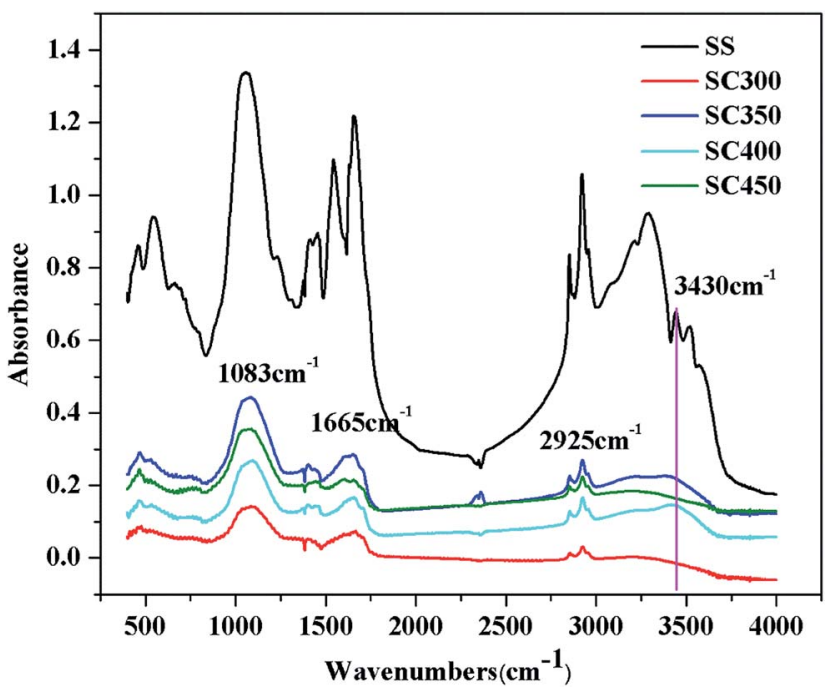

Fig. 1 The FTIR of sludge and biochar produced at different temperatures.

were as twice as that in sludge. There was no obvious change in the Cd content after pyrolysis. However, a decline was observed for the other four heavy metals. More than $59.9 \%, 74.9 \%$ and $87.8 \%$ reductions were seen in the biochar compared with the initial sludge for $\mathrm{Zn}, \mathrm{Cu}$ and $\mathrm{Ni}$, respectively, which meant that the pyrolysis had a positive influence on reducing the risk of $\mathrm{Zn}$, $\mathrm{Cu}$ and $\mathrm{Ni}$.

The heavy metal percentage was another indicator that helps determine the speciation distribution of heavy metals. The percentages of heavy metals in the $F_{1}$ category are presented in Fig. 2(b). Some variations appeared after pyrolysis: the percentage of fraction $F_{1}$ exhibited an obvious downward trend after pyrolysis for almost all heavy metals, most notably $\mathrm{Cu}$, Ni and $\mathrm{Zn}$. According to the calculations, the percentage of $\mathrm{Cu}\left(F_{1}\right), \mathrm{Ni}\left(F_{1}\right)$ and $\mathrm{Zn}\left(F_{1}\right)$ in biochar was less than $4 \%, 7 \%$ and $13 \%$, respectively. Arsenic also showed a downward trend after pyrolysis to a slight degree. All of this means that the process of pyrolysis could reduce the unstable fraction of $\mathrm{Cu}, \mathrm{Ni}, \mathrm{Zn}$ and As. However, the same trend did not appear in the $\mathrm{Cr}, \mathrm{Pb}$ and $\mathrm{Cd}$ data. In fact, the percentages of $\mathrm{Cr}, \mathrm{Pb}$ and $\mathrm{Cd}$ increased slightly after pyrolysis: more specifically, the percentage of $\mathrm{Cr}$ $\left(F_{1}\right)$ in biochar was higher than that in the sludge. The percentages of $\mathrm{Cd}\left(F_{1}\right)$ and $\mathrm{Pb}\left(F_{1}\right)$ both showed a slight downward trend only in lower temperature pyrolysis (Cd: $300{ }^{\circ} \mathrm{C}, \mathrm{Pb}: 350{ }^{\circ} \mathrm{C}$ ).

A previous pyrolysis study ${ }^{24}$ of pulp/paper indicated that increasing temperature reduces the risk from heavy metals. However, in our study of microwave heating, higher temperature did not have a positive influence on the enhancement of heavy metal stabilization. Looking at the heavy metal contents and percentages in the exchangeable fraction $\left(F_{1}\right)$, it can be concluded that high temperature even increased the contents or percentages of the exchangeable forms, which meant that the risk of biochar would be increased during application.

Although the fractions bound to Fe and Mn oxides $\left(F_{2}\right)$ and the fraction associated with organic matter $\left(F_{3}\right)$ were actually more stable than the $F_{1}$, they were also still bioavailable and potentially labile when they went into the biosphere or the complex internal environment of living organisms. ${ }^{22}$ The $F_{2}$ fraction is thermodynamically unstable, which meant it could become available in an oxygen-deficient environment, and the $F_{3}$ fraction is easily transformed into $F_{2}$ and $F_{1}$ fractions in oxidizing conditions. Therefore, the potential risks of $F_{2}$ and $F_{3}$ fractions should not be overlooked. In Fig. 2(c), it could be seen that the content of heavy metals $\left(F_{2}\right.$ and $\left.F_{3}\right)$ in biochars were higher than in the sludge, and a similar tendency appeared in the percentage of heavy metals, apart from $\mathrm{Cu}$. Examining the content and percentage of $\mathrm{Cu}$ in fraction $F_{4}$, it could be found that most of the $\mathrm{Cu}$ fractions were transferred from $F_{1}, F_{2}$ and $F_{3}$ into $F_{4}$ through the process of pyrolysis.

The residual fraction was the most stable fraction and heavy metals could be held in the crystal structure. ${ }^{15}$ From Fig. 2(e) and (f), the content (fraction $F_{4}$ ) all heavy metals increased after pyrolysis. The percentages (fraction $F_{4}$ ) of $\mathrm{Cd}, \mathrm{Cr}, \mathrm{Ni}$ and $\mathrm{Pb}$ in biochar became lower than those in sludge, which indicated that the stable fraction of the four heavy metals were transferred into the unstable fraction after pyrolysis; but for $\mathrm{As}, \mathrm{Cu}$ and $\mathrm{Zn}$, the percentage of fraction $F_{4}$ decreased after the pyrolysis. This meant that these heavy metals were released during the pyrolysis procedure. This may be caused by the damage of the crystal structure in the sludge at high temperature.

Fig. 2 showed that the total content $\left(F_{1}+F_{2}+F_{3}+F_{4}\right)$ of zinc was higher than that of other heavy metals: this phenomenon was caused by the addition of zinc chloride, which acted as a chemical additive in the pyrolysis process. However, the most harmful fraction ( $F_{1}$, exchangeable or bound with carbonates) accounts for less than $3 \%$ of the total heavy metals in the biochar. More than $97 \%$ of the zinc was present in the fraction bound with $\mathrm{Fe}$ and $\mathrm{Mn}$ oxides $\left(F_{2}\right)$, organic matter or sulfides $\left(F_{3}\right)$ or non-silicate minerals $\left(F_{4}\right)$. In our previous leaching experiment, the concentration of zinc was also higher than other heavy metals, which meant there was a higher risk associated with this heavy metal. To reduce the risk caused by heavy metals, especially zinc chloride, the biochar should be washed with acid and deionized water many times prior to use. Reducing the dosage of zinc chloride or using alternative chemical additives with low risk will be studied in our future research.

A similar phenomenon occurred in the form changes of $\mathrm{Cu}$, As and $\mathrm{Cr}$. The $F_{4}$ fractions of $\mathrm{Cu}$, Ar and $\mathrm{Cr}$ with less potential bioavailability and mobility were the major fractions in the biochar. Based on this, most of the three heavy metals were probably contained in minerals like feldspars, quartz, etc. Some research ${ }^{\mathbf{1 7}}$ has indicated that $\mathrm{Cu}$ was mainly bound to sulfides in nature, meaning the solubility will increase under oxidizing conditions. Therefore, the oxygen-deficient environment in the pyrolysis procedure is helpful for the stabilization of $\mathrm{Cu}$ (Fig. 2).

$\mathrm{Cd}, \mathrm{Ni}$ and $\mathrm{Pb}$ were mainly found in the $F_{2}$ and $F_{3}$ fractions. Previous research has also found that the dominant fractions of $\mathrm{Cd}$ and $\mathrm{Pb}$ were oxidizable fractions $\left(F_{3}\right) .{ }^{17}$ This was because less bio-gas and bio-oil were produced at low temperature, which resulted in a relatively high organic matter content that then produced more fractions associated with organic matter in the 

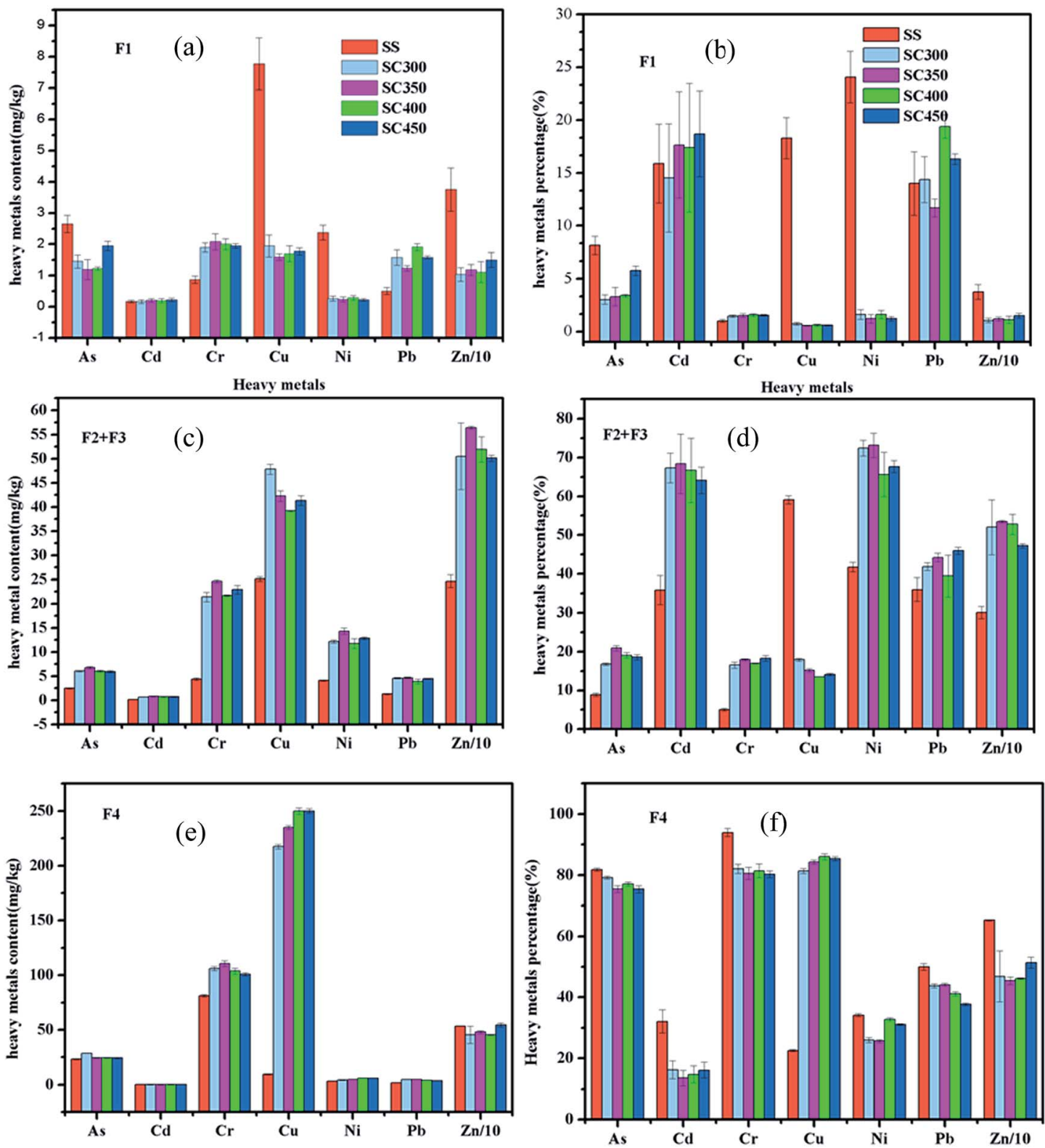

Fig. 2 Chemical speciation of heavy metals in sludge or biochars. The content of fraction $F_{i}=F_{i}(\mathrm{mg}) / \mathrm{sludge}$ or biochar (kg); the percentage of fraction $F_{i}=F_{i} /\left(F_{1}+F_{2}+F_{3}+F_{4}\right) \times 100 \%$.

biochar. The chemical speciation analysis indicated that not all the heavy metals were transferred from unstable into stable fractions.

Leaching characteristics is another indicator for heavy metals risk, namely the heavy metal's bio-availability and mobility to natural lixiviation. In our previous study, the leaching concentration of zinc (about $20 \mathrm{mg} \mathrm{kg}^{-1}$ ) was the highest among all the heavy metals. The addition of $\mathrm{ZnCl}_{2}$ is the main reason for the highest leaching concentration of $\mathrm{Zn}$. The second highest concentration was As and for the $\mathrm{Pb}, \mathrm{Ni}, \mathrm{Cd}$ and $\mathrm{Cu}$, the concentrations are less than $0.4 \mathrm{mg} \mathrm{kg}^{-1}$. It is also found that increasing temperature can reduce the leaching ability of heavy metals. In a word, there was some risk associated with the practical application of biochar based on the results of the leaching experiments and chemical forms.

\subsection{Risk analysis of heavy metals}

3.3.1 Risk assessment code (RAC). The risk assessment code was used to get more detailed insight on the environmental risk of heavy metals in sludge and biochar. The results are presented in Table $2 . \mathrm{Cr}, \mathrm{Cu}, \mathrm{Ni}$ and $\mathrm{Pb}$ in sludge presented low risk with an RAC of less than 9.1\%; and the other three heavy metals, As, Cd and Zn, were associated with medium risk with an RAC level between $10.7 \%$ and $21.1 \%$. After pyrolysis, the risk levels of As and $\mathrm{Zn}$ were changed markedly from MR to LR. Similarly, the risk level of Ni and Cu changed from LR to NR. In other words, the process of pyrolysis can reduce the risk of these four heavy metals. However, no prominent changes appeared in the RAC of Cd and Cr. Separately, the environmental risk of $\mathrm{Pb}$ was higher in biochar with the RAC moving from $4.3 \%$ (sludge) 
to $9.4-15.6 \%$ (biochar). To avoid this phenomenon, some fixing agent should be added into the sludge. As a whole, the environmental risk of heavy metals in sludge and biochar calculated with the RAC method was mostly low (mainly in LR and MR). Only the risk of $\mathrm{Pb}$ increased during the pyrolysis. The process of pyrolysis could reduce the risk of most heavy metals in sludge and provided a positive influence on the production of sludge.

3.3.2 Risk assessment based on the $\boldsymbol{I}_{\text {geo }}$. The calculated results of the $I_{\text {geo }}$ are presented in Table 2. The $I_{\text {geo }}$ of sludge was calculated to be between -0.6 and 2.6. The $I_{\text {geo }}$ of As in sludge was 0.2 , which meant it was in the category of UC to MC; but for the biochar, the $I_{\text {geo }}$ values were between 1.7 and 2.2, which were in the MC to HC bracket. For Cd, there was almost no change in the $I_{\text {geo }}$ after pyrolysis. The $I_{\text {geo }}$ of $\mathrm{Cr}$ in the sludge was -0.3 (UC); but in the biochar, the value was between 0.9 and 1.1 (UC-MC and MC). For $\mathrm{Cu}$, the $I_{\text {geo }}$ of the sludge was $1.6(\mathrm{MC})$, and the index of the biochars were between 2.7 and 2.9 (MC$\mathrm{MHC}$ ). The same tendency of $\mathrm{Ni}$ and $\mathrm{Zn}$ was exhibited as with the above-mentioned heavy metals. For $\mathrm{Pb}$, no changes were observed after pyrolysis: the $I_{\text {geo }}$ in sludge and biochar were both in the interval of UC. According to the $I_{\text {geo }}$ data, a huge rise in contamination occurred after pyrolysis. Other research has also indicated that the pyrolysis process can enable heavy metals in sludge to become concentrated, mostly in biochar, ${ }^{24}$ which gave rise to the increase in the $I_{\text {geo }}$.

3.3.3 Potential ecological risk (RI and $\boldsymbol{E}_{\mathbf{r}}$ ). The potential risks of single heavy metals $\left(E_{\mathrm{r}}\right)$ and total heavy metals (RI) are presented in Table 2. According to the Cd data, the $E_{\mathrm{r}}$ was high in both the sludge and the biochar. This may be due to the low background value. A huge increase in the $E_{\mathrm{r}}$ could be found after pyrolysis as well, indicating that the risk from $\mathrm{Cd}$ in biochar was more severe than that in the sludge, although some changes in the $E_{\mathrm{r}}$ of the other six heavy metals were observed during the pyrolysis process, the risk level posed by them was all LR or MR. From the RI, the total risk of the seven heavy metals was all in the CR level; but the risk of six heavy metals (Cd no included) was in the LR level, the potential risk was mainly caused by the presence of $\mathrm{Cd}$.

According to the GB/T23486-2009 standards in China, when soil $\mathrm{pH}$ was less than 6.5 , the $\mathrm{Cd}$ content should be lower than $5 \mathrm{mg} \mathrm{kg}{ }^{-1}$; and when the pH of soil was higher than 6.5, the Cd content should be lower than $20 \mathrm{mg} \mathrm{kg}^{-1}$. Although the $E_{\mathrm{r}}$ of $\mathrm{Cd}$ in biochar was mainly in the ME or HE category, the concentration was still within the standard. This study suggests that prior to sewage sludge biochar application, a risk analysis should be carried out on the background levels of local soil heavy metal contamination.

\subsection{Comparison of microwave heating and traditional heating}

It has been proven that biochar produced by microwave pyrolysis had a larger surface area and more porous structure; but few research has reported the differences between microwave heating and traditional heating on heavy metal stabilization. Chen et $a .^{14}$ have already done some research about the chemical forms of heavy metals in sludge-biochar produced by traditional heating ( $\mathrm{CH}$-biochar). The result showed that the percentage of oxidizable $\mathrm{Cu}\left(F_{3}\right)$ in the sludge-biochar was about $70 \%$, which meant that the oxidizable $\mathrm{Cu}$ was the major component. In our microwave sludge biochar (MW-biochar), the major component of $\mathrm{Cu}$ was the residual fraction $\left(F_{4}\right)$ with the percentage of $81.36-85.94 \%$. The $\mathrm{Zn}$ and $\mathrm{Pb}$ in $\mathrm{CH}$-biochar mainly existed as the fraction of $F_{2}$ and $F_{3}$, while in MWbiochar, the $\mathrm{Zn}$ and $\mathrm{Pb}$ were mainly distributed in the $F_{4}$ fraction with a percentage of about $50 \%$. The $\mathrm{Cr}$ and $\mathrm{Ni}$ in $\mathrm{CH}^{-}$ biochar were mainly concentrated in the $F_{4}$ fraction with a percentage of $53.20 \%$ and $50.35 \%$, respectively. Similarly, the main fraction of $\mathrm{Cr}$ (about 80\%) and $\mathrm{Ni}$ (about 40\%) in MWbiochar were in the residual fraction $\left(F_{4}\right)$. By contrasting $\mathrm{CH}$ and MW heating, it can be concluded that microwave heating has more advantages towards stabilizing the heavy metals $\mathrm{Cu}$, $\mathrm{Zn}, \mathrm{Pb}$ and $\mathrm{Cr}$.

\subsection{Future work}

It is well known that pyrolysis conditions (i.e. pyrolysis temperature, retention time and heating rate) critically influence the surface characteristics of biochar and even affect the distribution of pyrolysis products between biochar, bio-oil and bio-gas. But for heavy metal stabilization, researchers have mainly focus on the influence of temperature in traditional pyrolysis and overlook the potential impact of the retention time and heating rate. In this study, we only focused on the temperature variation in microwave heating. The influence of retention time and heating rate on the heavy metals contents and chemical forms should be studied in future experiments.

In this study, due to the reason that heavy metals were mainly concentrated in the biochar when the heating temperature is below $505{ }^{\circ} \mathrm{C},{ }^{\mathbf{1 6}}$ our primary research only examined the concentration and chemical forms of heavy metals in biochar. But in high temperature pyrolysis, more heavy metals are likely to emerge in the bio-oil or bio-gas and the heavy metal distribution will become more complicated. In this case, researchers should not only focus on the heavy metals in biochar, but also think about the mass balance of heavy metals in the biochar, bio-oil and bio-gas to facilitate a more comprehensive evaluation on heavy metal stabilization during the pyrolysis process.

\section{Conclusions}

(1) By means of heavy metals fraction analysis (including exchangeable, reducible, oxidizable and residual fraction), stabilization of $\mathrm{As}, \mathrm{Ni}, \mathrm{Cu}$ and $\mathrm{Zn}$ were strengthened after pyrolysis. Meanwhile the stabilization was reduced for $\mathrm{Cd}, \mathrm{Pb}$ and $\mathrm{Cr}$.

(2) Total heavy metals are enriched in the pyrolysis process according to the risk assessment of $I_{\text {geo }}$ Pb and $\mathrm{Cd}$ were in relatively high levels in biochar after pyrolysis through risk assessment of the RAC and $E_{\mathrm{r}}$. More attention to these two metals should be paid during biochar application.

(3) In the range of $300-450{ }^{\circ} \mathrm{C}$, increasing microwave pyrolysis temperature does not have a definite or positive influence 
on the heavy metal stabilization based on the chemical speciation and risk assessment from this research.

(4) Compared with traditional heating, microwave heating has more advantages on stabilizing the heavy metals $\mathrm{Cu}, \mathrm{Zn}, \mathrm{Pb}$ and $\mathrm{Cr}$.

\section{Acknowledgements}

This work is financially supported by the Major Science and Technology Program for Water Pollution Control and Treatment of China (no. 2015ZX07203-005, 2015ZX07203-007, 2012ZX07202-005).

\section{Notes and references}

1 G. Yang, G. M. Zhang and H. C. Wang, Water Res., 2015, 78, 60-73.

2 J. Y. Zhang, C. Lv, J. Tong, J. W. Liu, J. B. Liu, D. W. Yu, Y. W. Wang, M. X. Chen and Y. S. Wei, Bioresour. Technol., 2016, 200, 253-261.

3 K. M. Smith, G. D. Fowler, S. Pullket and N. J. D. Graham, Water Res., 2009, 43, 2569-2594.

4 J. B. Liu, D. W. Yu, J. Zhang, M. Yang, Y. W. Wang, Y. S. Wei and J. Tong, Water Res., 2016, 98, 98-108.

5 J. B. Liu, Y. S. Wei, K. Li, J. Tong, Y. W. Wang and R. L. Jia, Water Res., 2016, 90, 225-234.

6 X. D. Song, X. Y. Xue, D. Z. Chen, P. J. He and X. H. Dai, Chemosphere, 2014, 109, 213-220.

7 B. A. Mohamed, C. S. Kim, N. Ellis and X. Bi, Bioresour. Technol., 2016, 201, 121-132.

8 T. Xie, K. R. Reddy, C. Wang, E. Yargicoglu and K. Spokas, Crit. Rev. Environ. Sci. Technol., 2015, 45, 939-969.

9 X. F. Tan, Y. G. Liu, G. M. Zeng, X. Wang, X. J. Hu, Y. L. Gu and Z. Z. Yang, Chemosphere, 2015, 125, 70-85.

10 Y. Liu, X. N. Wang, J. Wang, Y. G. Nie, H. Du, H. Dai, J. J. Wang, M. D. Wang, S. P. Chen, T. K. Hei, Z. X. Deng, L. J. Wu and A. Xu, Environ. Sci. Technol., 2016, 50, 3154-3164.

11 Q. H. Lin, G. Y. Chen and Y. K. Liu, J. Anal. Appl. Pyrolysis, 2012, 94, 114-119.

12 L. Zhao, X. D. Cao, O. Masek and A. Zimmerman, J. Hazard. Mater., 2013, 256, 1-9.

13 M. Inyang, B. Gao, Y. Yao, Y. Xue, A. R. Zimmerman, P. Pullammanappallil and X. Cao, Bioresour. Technol., 2012, 110, 50-56.

14 F. F. Chen, Y. Y. Hu, X. M. Dou, D. Z. Chen and X. H. Dai, J. Anal. Appl. Pyrolysis, 2015, 116, 152-160.

15 X. Yuan, H. Huang, G. Zeng, H. Li, J. Wang, C. Zhou, H. Zhu, X. Pei, Z. Liu and Z. Liu, Bioresour. Technol., 2011, 102, 41044110.
16 R. C. Kistler, F. Widmer and P. H. Brunner, Environ. Sci. Technol., 1987, 21, 704-708.

17 Y. D. He, Y. B. Zhai, C. T. Li, F. Yang, L. Chen, X. P. Fan, W. F. Peng and Z. M. Fu, Environ. Technol., 2010, 31, 567574.

18 P. Devi and A. K. Saroha, Bioresour. Technol., 2014, 162, 308315.

19 D. C. Su and J. W. C. Wong, Environ. Int., 2004, 29, 895-900.

20 C. W. Jin, S. J. Zheng, Y. F. He, G. D. Zhou and Z. X. Zhou, Chemosphere, 2005, 59, 1151-1159.

21 S. Tandy, J. R. Healey, M. A. Nason, J. C. Williamson and D. L. Jones, Bioresour. Technol., 2009, 100, 4220-4226.

22 H. M. Li, X. Qian, W. Hu, Y. L. Wang and H. L. Gao, Sci. Total Environ., 2013, 456, 212-221.

23 I. Walter, F. Martinez and V. Cala, Environ. Pollut., 2006, 139, 507-514.

24 X. Z. Yuan, L. J. Leng, H. J. Huang, X. H. Chen, H. Wang, Z. H. Xiao, Y. B. Zhai, H. M. Chen and G. M. Zeng, Chemosphere, 2015, 120, 645-652.

25 H. Bing, J. Zhou, Y. Wu, X. Wang, H. Sun and R. Li, Environ. Pollut., 2016, 214, 485-496.

26 L. Hakanson, Water Res., 1980, 14, 975-1001.

27 T. Yu, F. Lin and H. J. Li, Soil Sediment Contam., 2007, 16, 605-615.

28 L. L. Wang, X. Z. Yuan, H. Zhong, H. Wang, Z. B. Wu, X. H. Chen and G. M. Zeng, Chem. Eng. J., 2014, 258, 334340.

29 X. J. Wang, X. M. Xu, X. Liang, Y. Wang, M. Liu, X. Wang, S. Q. Xia, J. F. Zhao, D. Q. Yin and Y. L. Zhang, J. Hazard. Mater., 2011, 192, 1226-1233.

30 D. Nassini, G. G. Fouga, H. E. Nassini and A. E. Bohe, Fuel, 2016, 182, 623-631.

31 X. Yuan, L. Leng, H. Huang, X. Chen, H. Wang, Z. Xiao, Y. Zhai, H. Chen and G. Zeng, Chemosphere, 2015, 120, 645-652.

32 T. B. Chen, Y. M. Zheng, H. Chen and G. D. Zheng, Environ. Sci., 2004, 25, 117-122, in chinese.

33 R. H. Li, J. J. Wang, B. Y. Zhou, M. K. Awasthi, A. Ali, Z. Q. Zhang, A. H. Lahori and A. Mahar, Bioresour. Technol., 2016, 215, 209-214.

34 L.-g. Yan, K. Yang, R.-r. Shan, T. Yan, J. Wei, S.-j. Yu, H.-q. Yu and B. Du, J. Colloid Interface Sci., 2015, 448, 508-516.

35 H. S. Kambo and A. Dutta, Renewable Sustainable Energy Rev., 2015, 45, 359-378.

36 E. J. Leijenhorst, W. Wolters, L. van de Beld and W. Prins, Fuel Process. Technol., 2016, 149, 96-111. 